\title{
Displacement control of isolated structures with semi-active control devices
}

\author{
Chin-Hsiung $\operatorname{Loh}^{1, *, \dagger}$, L. Y. Wu and P. Y. $\operatorname{Lin}^{2}$ \\ ${ }^{1}$ Department of Civil Engineering, National Taiwan University, Taipei, Taiwan \\ ${ }^{2}$ National Center for Research on Earthquake Engineering, Taipei, Taiwan
}

\begin{abstract}
SUMMARY
This study investigates the application of a semi-active control method utilizing a magnetorheological (MR) damper to reduce the response of an isolated structure subjected to earthquake excitations. A series of performance tests were carried out on a $2 \mathrm{kN}$ MR damper and the Bouc-Wen model was utilized to establish the numerical model of the MR device. A fuzzy logic control algorithm was then applied to establish the controller. Results of numerical simulation indicated that the established control algorithm is useful to reduce displacement and acceleration responses of base-isolated structures. Copyright (C) 2003 John Wiley \& Sons, Ltd.
\end{abstract}

KEY WORDS: fuzzy logic control; nonlinear hysteretic model; semi-active control

\section{INTRODUCTION}

For the past few years there has been a rapid growth in the development and application of structural energy dissipation devices for earthquake and wind hazard mitigation. The idea behind these devices is to enhance the structural energy dissipation capacity against moderate and strong external loadings, such as earthquake and wind, and to reduce natural hazards without compromising the safety and economy of the structure itself. The use of energy dissipation devices for vibration reduction of structures has been used for retrofitting and updating of existing buildings and for new constructions. These energy dissipation devices include: rubber bearings, viscoelastic dampers, friction dampers and plastically deforming metals. Passive control devices in the form of tuned mass dampers and base isolation systems have also been employed with good results. Most of these devices have been considered for seismic and wind-resistant design.

When an active control system is applied to the civil infrastructure to reduce the structural response under external excitation, some critical issues arise even for a simple structure system. The issues include the following: (1) the reliability, feasibility and effectiveness of different active control methods; (2) too many degrees of freedom in a real structural system with limited information available from the structural response measurement; (3) the maximum control force

*Correspondence to: Chin-Hsiung Loh, Department of Civil Engineering, National Taiwan University, Taipei, Taiwan.

†E-mail: lohc@ncree.gov.tw 
generated by the actuator is limited. The most effective way to solve these problems is to perform an experimental verification of a structure with the implementation of active control devices, taking these three issues into account. Besides the active control system, lower power consumption, higher reliability and fail-safe mechanisms make the semi-active control technique one of the promising approaches for the seismic mitigation of civil engineering structures.

Semi-active control systems can provide reliability of passive devices and adaptability of active control systems, and need very low power supply compared with active control systems. Lower power consumption, higher reliability and fail-safe mechanisms make the semi-active control technique a promising approaches for the seismic mitigation of civil engineering structures. The magnetorheological (MR) damper resembles an ordinary linear viscous damper, but the cylinder of the MR damper is filled with special fluid that contains very small polarizable particles. The fluid in the damper chamber can be changed from liquid to solid and vice versa by adjusting the magnitude of the magnetic field produced by the coil surrounding the piston head of a MR damper. When no current is supplied to the coil, a MR damper behaves as an ordinary viscous damper. On the other hand, when current is sent through the coil, the fluid inside a MR damper becomes semi-solid and its yield strength depends on the current applied to it. In this study, the seismic response of an isolated system controlled by semi-active control systems utilizing MR dampers was studied [1-4]. The control force is not applied directly to the structure, but is utilized to adjust the parameters of a MR damper in order to provide the energy dissipation capability. Control instability never occurs and only small amount of energy is required. Therefore, MR dampers are reliable and fail-safe.

A major character of MR dampers are their inherent nonlinearity [4-6]. The control algorithm of semi-active control systems utilizing variable fluid dampers [7-9] or MR dampers $[10,11]$ have been discussed by many researchers. Experimenal research has been key to understanding the behavior of the MR fluid and its function within a damper. In this study, the Bouc-Wen model was utilized to establish a numerical model of the MR device in order to simulate the control fesibility. A fuzzy logic control algorithm was then utilized to determine the command voltage of the MR damper. Through numerical simulation, the effectiveness of an isolated system controlled by MR dampers using the fuzzy logic control algorithm was investigated.

\section{NUMERICAL MODEL OF MR DAMPER}

Magnetorheological (MR) fluid dampers are receiving a great deal of attention among are advocates of semi-active control devices. In this study a numerical model of the forcedisplacement relationship of the MR damper is developed from which a semi-active control algorithm can also be examined.

\subsection{Performance test}

A small, commercially available MR fluid-based damper, RD-1005-3 $3 \mathrm{kN}$ MR damper was used for a series of performance tests. Test procedures included using different values of excitation frequency, voltage and stroke applied to the damper, as shown in Table I. A sinusoidal displacement, constant voltage test was used to study the effect of voltage to the 
Table I. Performance tests.

\begin{tabular}{lcc}
\hline \multicolumn{3}{c}{ Sinusoidal displacement/constant voltage } \\
\hline Frequency $(\mathrm{Hz})$ & Voltage $(\mathrm{V})$ & Stroke $(\mathrm{mm})$ \\
0.5 & $0,1,2,3,4$ & $5,10,15$ \\
1 & $0,1,2,3,4$ & $5,10,15$ \\
2 & $0,1,2,3,4$ & $5,10,15$ \\
\hline \multicolumn{3}{c}{ Random displacement/constant voltage } \\
\hline Frequency $(\mathrm{Hz})$ & Voltage $(\mathrm{V})$ & Maximum stroke $(\mathrm{mm})$ \\
& $0,1,2,3,4$ & $30,40,50,60$ \\
\hline Frequency $(\mathrm{Hz})$ & Random displacement/random voltage \\
& Voltage $(\mathrm{V})$ & Maximum stroke $(\mathrm{mm})$ \\
\hline
\end{tabular}

influence of hysteretic behavior of the MR damper. A set of system parameters under different levels of constant voltage $(0.0,1.0,2.0,3.0$, and $4.0 \mathrm{~V})$ was developed. A random displacement, constant voltage performance test was also conducted in order to establish a numerical model of the MR damper by a system identification technique. The results from a random displacement, random voltage test is utilized to validate the accuracy of the numerical model. The characteristic of the MR damper depends on voltage, displacement stroke and frequency. Figure 1 shows the voltage- and frequency-dependent hysteretic loop (force versus stroke) of the damper. The maximum force provided by the damper increases with the increase of voltage, displacement stroke and frequency.

\subsection{Theoretical model for MR damper restoring force: Bouc-Wen model}

To represent the force-response relationship of the MR damper, the Bouc-Wen model was used. The total restoring force $F(t)$ is expressed as:

$$
\begin{gathered}
F(t)=C(V) \dot{x}(t)+z(t) \\
\dot{z}(t)=A \dot{x}(t)+\beta|\dot{x}(t) \| z(t)|^{n-1} z(t)+\gamma \dot{x}(t)|z(t)|^{n}
\end{gathered}
$$

where $C(V)$ is a voltage-dependent parameter and $z(t)$ is the restoring force. This Bouc-Wen hysteretic model is capable of representing a wide variety of hysteretic, deteriorating types of behavior involving cyclic energy dissipation and displacement. The model parameters $\beta, \gamma$ and $n$ determine the hysteretic shape and $A$ the tangent stiffness. Based on a linear parameterized estimator for the on-line estimation of the hysteretic behavior of the model, the modification on the model restoring force expressed in discrete form was shown as follows [12]:

$$
\dot{z}(t)=A \dot{x}(t)+\sum_{n=1}^{N} a_{n}\left[\beta|\dot{x}(t)||z(t)|^{n-1} z(t)+\gamma \dot{x}(t)|z(t)|^{n}\right]
$$



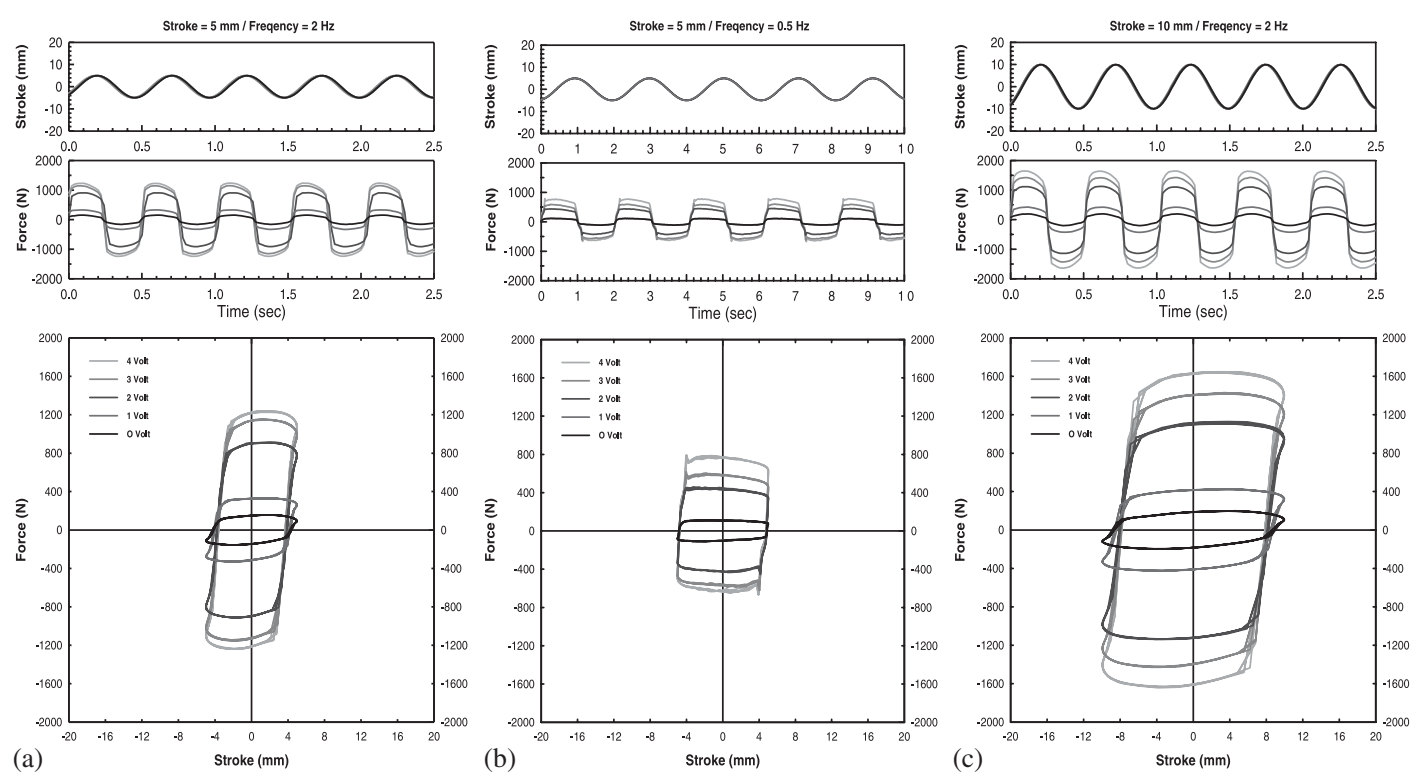

Figure 1. Plot of force-displacement (or stroke) relationship from cyclic loading tests of $3 \mathrm{kN}$ MR damper for different voltages $(0.0,1.0,2.0,3.0,4.0 \mathrm{~V}$, respectively); (a) $2.0 \mathrm{~Hz}$ cyclic loading, stroke $5.0 \mathrm{~mm}$; (b) $0.5 \mathrm{~Hz}$ cyclic loading, stroke $5.0 \mathrm{~mm}$; (c) $2.0 \mathrm{~Hz}$ cyclic loading, stroke $10 \mathrm{~mm}$.

A discrete time form of Equation (3) is defined as follows:

$$
\begin{aligned}
z(k) & =z(k-1)+\Delta t A \dot{x}(k-1) \\
& +\Delta t \sum_{n=1}^{N} a_{n}\left[\beta|\dot{x}(k-1)||z(k-1)|^{n-1} z(k-1)+\gamma \dot{x}(k-1)|z(k-1)|^{n}\right]
\end{aligned}
$$

This discrete time model gives rise to the following discrete-time linearly parameterized estimator, shown in Equation (5):

$$
\begin{aligned}
z(k) & =z(k-1)+\theta_{0}(k) \dot{x}(k-1) \\
& +\sum_{n=1}^{N}\left[\theta_{2 n-1}(k)|\dot{x}(k-1)||z(k-1)|^{n-1} z(k-1)+\theta_{2 n}(k) \dot{x}(k-1)|z(k-1)|^{n}\right]
\end{aligned}
$$

where the coefficients $\theta_{i}, i=0, \ldots, 2 N$ are estimates at each time $t_{k}$ of the corresponding coefficients shown in Equation (4); i.e. $\theta_{0}$ is an estimate of $\Delta t A, \theta_{2 n-1}$ is an estimate of, $\Delta t a_{n} \beta$, and $\theta_{2 n}$ is an estimate of $\Delta t a_{n} \gamma$. Equation (5) indicates a linear parameterized form with respect to $\theta_{i}, i=0, \ldots, 2 N$. Now set

$$
\theta=\left[\theta_{0}, \theta_{1}, \theta_{2}, \cdots \theta_{2 N}\right]^{\mathrm{T}}
$$


where $\theta_{i}$ is a function of $\Delta t$ and time-dependent model parameters. Also define

$$
\begin{aligned}
\phi(k-1)= & {\left[\dot{x}(k-1)|\dot{x}(k-1)||z(k-1)|^{0} z(k-1) \quad \dot{x}(k-1)|z(k-1)|^{1}\right.} \\
& |\dot{x}(k-1)| \mid z\left(k-\left.1\right|^{1} z(k-1) \quad \dot{x}(k-1)|z(k-1)|^{2} \ldots \ldots \ldots\right. \\
& \left.\left.\left|\dot{x}(k-1) \| z(k-1)^{N-1} z(k-1) \quad \dot{x}(k-1)\right| z(k-1)\right|^{N}\right]
\end{aligned}
$$

Then the restoring force at time $\mathrm{t}$ can be expressed as

$$
z(k)=z(k-1)+\phi^{\mathrm{T}}(k-1) \theta
$$

Based on the data collected from performance test, least-square method was used to estimate the model parameters, $\theta_{i}, i=0, \ldots, 2 N$, for each discrete frequency.

\subsection{Voltage-dependent MR model}

From Equations (3)-(5) the model parameters for the restoring force are only for a specified voltage. Based on the experimental data from several random displacement/constant voltage performance tests, as discussed above, and adapted to the system identification method, the voltage-dependent parameter vector $\theta$ can be identified under different test cases. In this study $N=5$ is used. The total restoring force is now defined as:

$$
\tilde{F}(k)=z(k)+C(V(k)) \dot{x}(k)
$$

and

$$
z(k)=z(k-1)+\theta_{0}(V(k)) \phi_{1}+\sum_{i=1}^{4} \theta_{i}(V(k)) \phi_{i+1}(k) \mathrm{d} t
$$

The error function can be defined as the $e(k)=\tilde{F}(k)-Q(k)$ and $Q(k)$ is the measure force from the performance test that the MR damper can provide. The least-squares minimization method can be applied to identify the model parameters. To generate a robust numerical model of the MR damper subject to different types of excitation, several kinds of random excitation with different stroke limits and frequency contents (i.e. random displacement and constant voltage, RDCV) are used to conduct the performance test of the MR damper. Then, the test results are used for system identification. Figure 2 shows the estimated model parameters as a function of voltage. Finally, through polynomial interpolation, as shown in Figure 2, the voltage-dependent model parameters of the MR damper can be obtained. The restoring force can be expressed by Equations (6) and (7), and the voltage-dependent model parameters are shown in Equation (8) through regression analysis:

$$
\left.\begin{array}{c}
\theta_{0}(V(k))=-14.4691 V(k)^{3}-5.7867 V(k)^{2}+548.9399 V(k)+62.2524 \\
\theta_{1}(V(k))=42.6491 V(k)^{2}+4.1379 V(k)-767.6513 \\
\theta_{2}(V(k))=25.3443 V(k)^{2}+56.4777 V(k)-333.2166 \\
\theta_{3}(V(k))=60.2530 V(k)^{2}-334.4931 V(k)-96.8077 \\
\theta_{4}(V(k))=31.1447 V(k)^{2}-197.0355 V(k)-63.7788 \\
C(V(k))=0.5+0.875 V(k)
\end{array}\right\}
$$



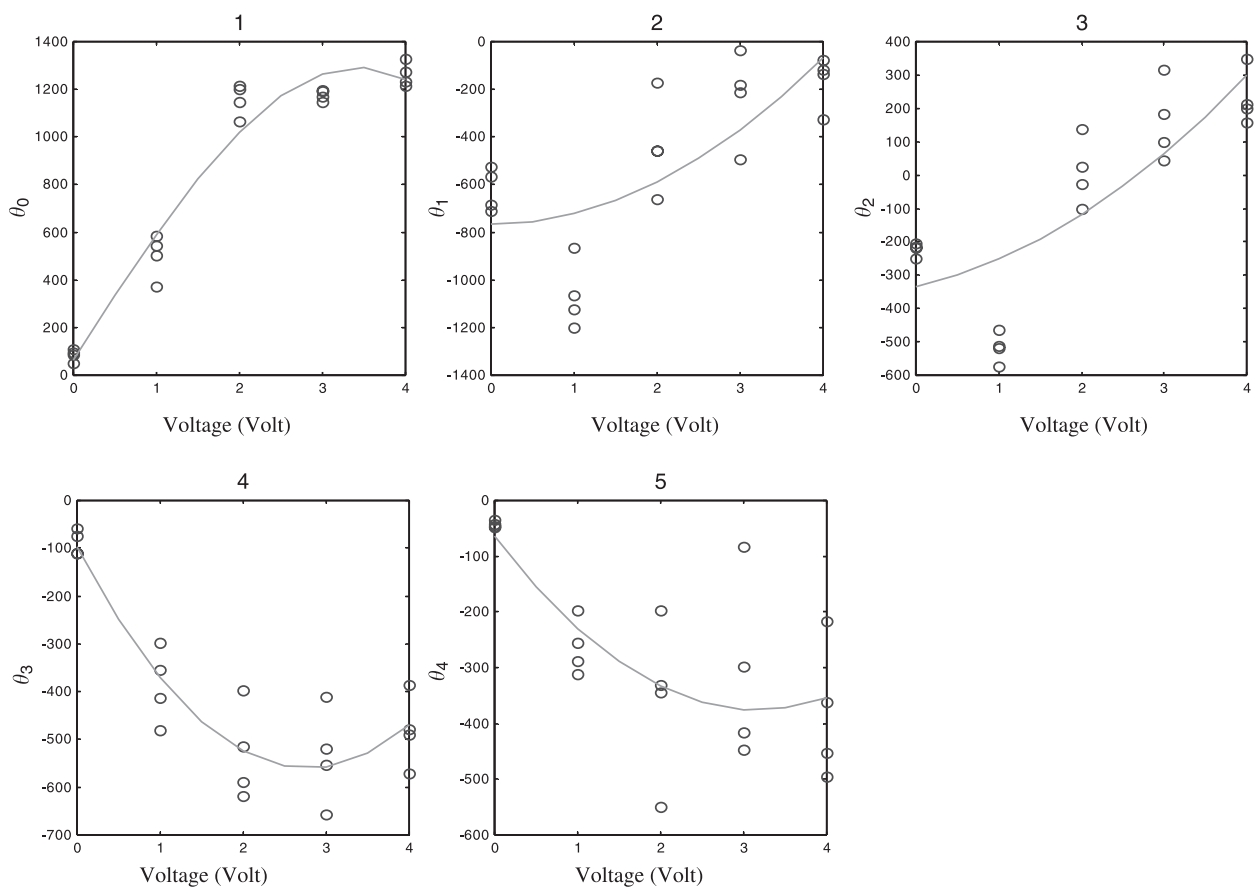

Figure 2. Estimated model parameters of damper restoring force $\theta_{i}(i=0-4)$, as a function of voltage, shown in Equation (8). Small circles indicated experimental data, solid line indicates regression curve.

where $\phi_{1}(k)=\dot{x}(k), \quad \phi_{2}(k)=|\dot{x}(k)| z(k), \phi_{3}(k)=\dot{x}(k)|z(k)|, \quad \phi_{4}(k)=|\dot{x}(k)||z(k)| z(k)$, and $\phi_{5}(k)=$ $\dot{x}(k)|z(k)|^{2}$. These system parameters are all function of voltages (units $\mathrm{kN}, \mathrm{m}, \mathrm{V}, \mathrm{s}$ ). Through the nonlinear regression of model parameters with respect to voltage, the voltage-dependent parameters were established. Equations (6)-(8) show that the restoring force of the MR damper depends on voltage and stroke. The proposed model is only for the RD-1005-3 $3 \mathrm{kN}$ MR damper and the model parameters are voltage-dependent.

To verify the accuracy and robustness of the identified model, additional experimental tests, random displacement and random voltage RDRV, are conducted. Figure 3 shows one of the validation test results. Although the voltage-dependent model parameters are obtained from regression (as shown in Figure 2) and the deviation of data to the regression line is not fitted very well (a large coefficient of variation was observed), the proposed model can predict the damper behavior quite well, even for the case of random voltage input. The proposed voltagedependent MR model is only for the RD-1005-3 $3 \mathrm{kN}$ MR damper. The identified model can be used for simulation studies in order to verify the applicability of MR damper. From this performance test of the specified MR damper, it is concluded that only very limited power needs to be supplied to the damper so as to gain the restoring force. A small voltage is supplied to the MR damper, based on the proposed model, and the restoring force can be developed with specified stroke. 

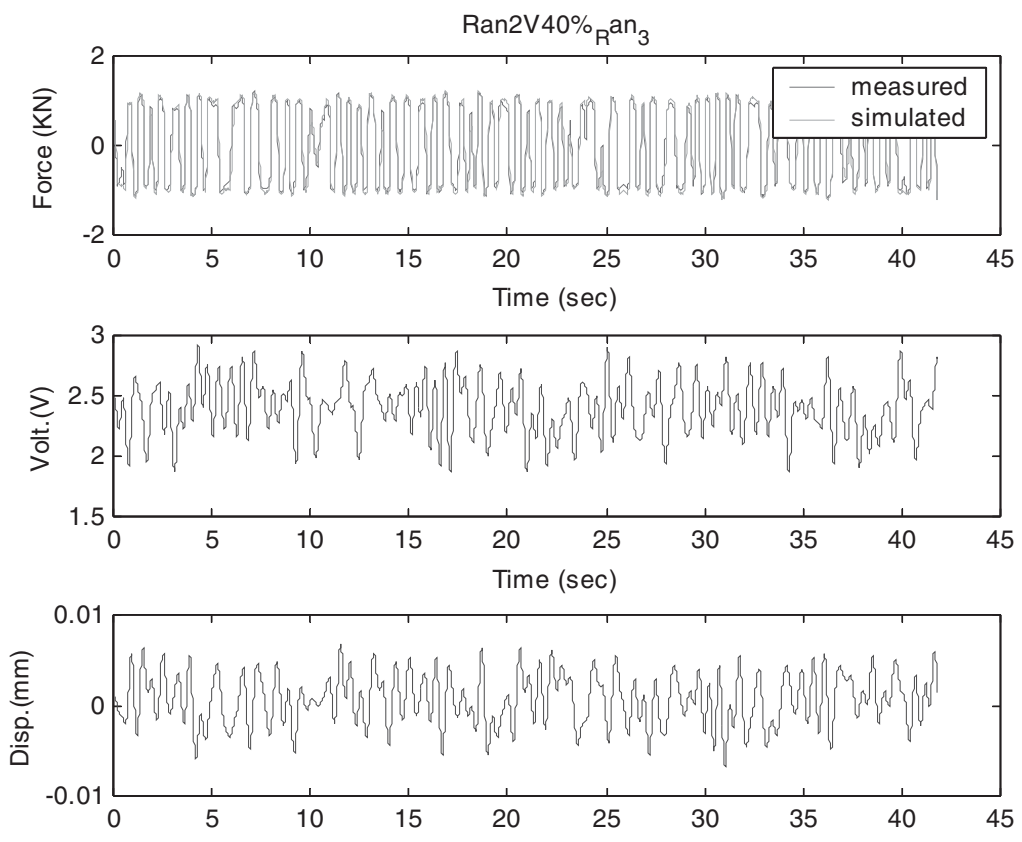

(a)

Time (sec)
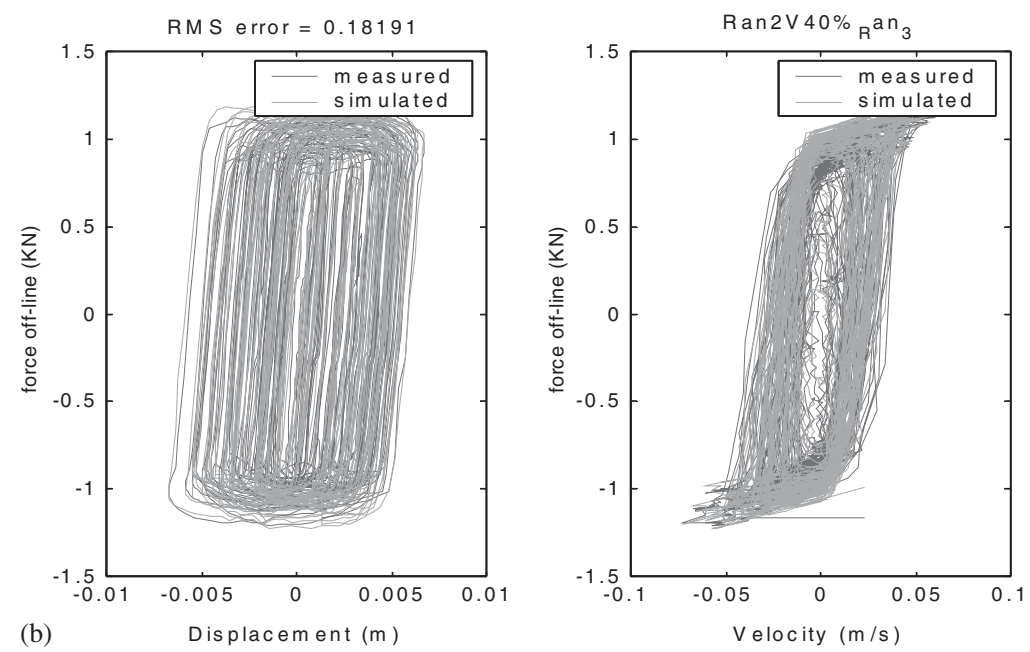

Figure 3. Validation test of the proposed model of MR damper and the experimental test data: (a) measured and simulated damper force exerted by the damper (voltage applied to the damper, and displacement of the damper also shown); (b) comparison between the numerical simulation and experimental results for force-displacement and force-voltage relationship.

\section{NUMERICAL SIMULATION OF SDOF ISOLATED SYSTEM}

Generally for a structure with an isolation system, its period will be lengthened and the displacement will also be enlarged. To avoid large displacement of the isolation system some 
devices can be implemented to reduce the displacement in order to protect the deformation of the isolator not to reach its ultimate deformation. The purpose of this simulation is to verify the effectiveness of the MR damper to reduce the displacement of an isolation system. Consider a single-degree-of-freedom (SDOF) system with base isolation system. Besides the isolation system, a semi-active control device (MR damper) was also implemented. A bilinear model hysteretic model was used to represent the restoring force of the isolator and a small inherent viscous damping ratio $1.5 \%$ was also utilized to modify the isolation system, as shown in Figure 4. In actual application, the design of the isolation system was suggested by using the Taiwan Structure Design Code for isolation systems. In this study two kinds of soil condition were considered, soil type 1 (rock and stiff soils) and soil type 4 (Taipei basin). By adapting the Taiwan Seismic Design Code, a zone factor $Z=0.33$ is selected in soil type 1 and $Z=0.23$ for soil type 4, and the mass of the SDOF system is assigned as $M=2400$ ton. The effective period of the system is $T_{\mathrm{e}}=2.5 \mathrm{~s}$. The number of bearings $m=2$, and the equivalent damping ratio of the isolator $\xi_{\mathrm{e}}=0.2$. The initial-stiffness-to-post-yielding-stiffness ratio of the isolator hysteretic behavior $\alpha=K_{\mathrm{u}} / K_{\mathrm{d}}$ is set to 20 (where $K_{\mathrm{u}}$ is pre-yield stiffness and $K_{\mathrm{d}}$ is post-yield stiffness). According to the design code, the design value of the isolator was obtained and summarized in Table II. The maximum displacement of the controller $D_{\max }$ is set to $1.5 D_{\mathrm{d}}$ where $D_{\mathrm{d}}$ is the design displacement, and this design displacement will be used to design the fail-safe system. Design displacement $D_{\mathrm{d}}$, design velocity $V_{\mathrm{d}}$ and design acceleration $A_{\mathrm{d}}$ are utilized to specify the control limits of the controller.

Two ground motions data were selected to represent type 1 and type 4 soil conditions in this study. Each ground motion excitation is normalized to several levels of peak ground acceleration (PGA). For soil type 1, three levels of ground motion intensity were used $\mathrm{PGA}=0.1 \mathrm{~g}, 0.33 \mathrm{~g}$ (design level) and $0.5 \mathrm{~g}$, respectively. For case of soil type 4 , it is assumed

\section{specify}

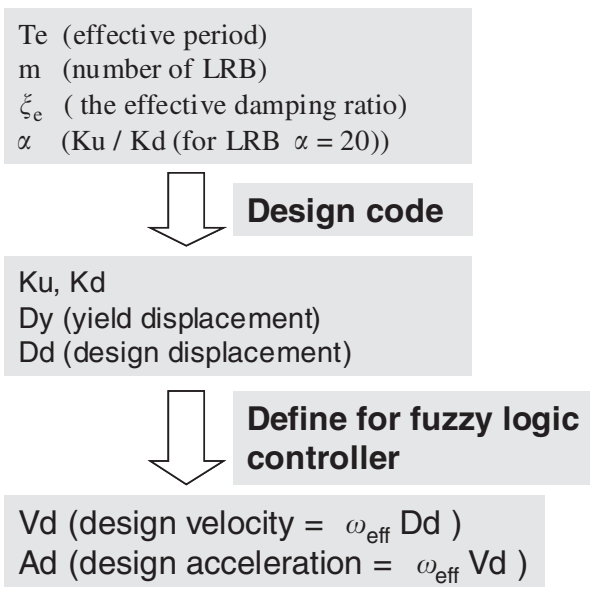

(a)

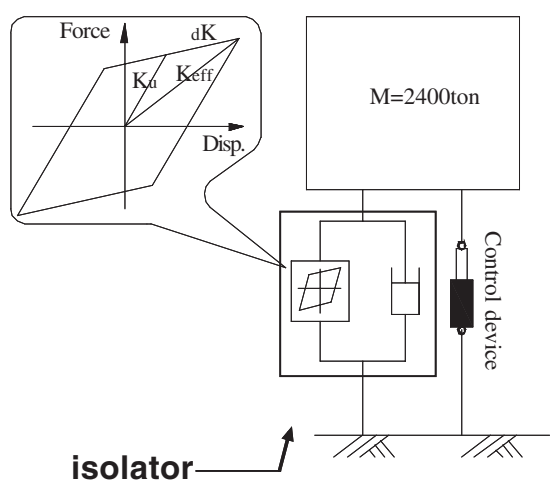

(b)

Figure 4. (a) Flow chart of the required model parameters for an inelastic single-degree-of-freedom system (bilinear model) procedures for performing semi-active control. The isolator was modeled as a bilinear hysteretic model. The design procedure for isolation system and the implementation of fuzzy logic controller are shown. (b) Single-degree-of-freedom isolated system implemented with an MR damper. 
Table II. Design paramaters of a Single-degree-of-freedom system with base isolation.

\begin{tabular}{lrrr}
\hline & Type_1 & Type_4 & Units \\
\hline$T_{\mathrm{e}}$ & 2.50 & 2.50 & $\mathrm{sec}$ \\
$\alpha$ & 20.00 & 20.00 & \\
$\xi_{\mathrm{e}}$ & 0.20 & 0.20 & $\mathrm{kN} / \mathrm{m}$ \\
$K_{\mathrm{u}}$ & 102749.23 & 102749.23 & $\mathrm{kN} / \mathrm{m}$ \\
$K_{\mathrm{d}}$ & 5137.46 & 5137.46 & $\mathrm{~m}$ \\
$D_{\mathrm{y}}$ & 0.0029 & 0.0079 & $\mathrm{~m}$ \\
Design_d & 0.1145 & 0.3163 & $\mathrm{~m}$ \\
$D_{\max }$ & 0.1718 & 0.4744 & $\mathrm{~m} / \mathrm{s}$ \\
$V_{\mathrm{d}}$ & 0.2879 & 0.7948 & $\mathrm{~m} / \mathrm{s}^{-2}$ \\
$A_{\mathrm{d}}$ & 0.7235 & 1.9976 & \\
\hline
\end{tabular}

that PGA $=0.1 \mathrm{~g}, 0.23 \mathrm{~g}$ (design level), $0.33 \mathrm{~g}$ and $0.5 \mathrm{~g}$, respectively. For each intensity level of ground excitation five control algorithms were selected and analyzed: (1) uncontrolled case (isolator only); (2) passive-off case (isolation system controlled by MR damper with voltage $V_{\min }=0.0 \mathrm{~V}$ ); (3) passive-on (isolation system controlled by MR damper with voltage $V_{\max }=$ $4.0 \mathrm{~V}),(4)$ passive-on with fuzzy logic control (isolation system controlled by MR damper where the voltage was determined by means of a fuzzy logic controller); and (5) control by viscous damper (isolation system controlled by viscous damper). These five different control arrangements are all expressed in passive control except case (4). The effectiveness of the four different passive control cases will be compared with the case (4) which is the semi-active control using the MR damper. In case (5) it is assumed that the viscous damper does not provide any stiffness and may not increase the acceleration response to the flexible structure such as the structure with base isolation. In this study, installation of the viscous damper was chosen as the best passive control case in order to compare the structure using semi-active control devices (i.e. MR damper). The viscous damping ratio of the viscous damper is set at $C=1500 \mathrm{kN} \mathrm{m} \mathrm{s}^{-1}$ which is assumed as the best performance for the viscous damper.

\subsection{Design of the fuzzy logic controller}

The membership function for the fuzzy logic controller is specified in Figure 5. The relative displacement, relative velocity and absolute acceleration responses were utilized as the feedback signals of the control system. The output signal is the command voltage. The linguistic values of the membership functions are: $\mathrm{P}$ positive; $\mathrm{N}$ negative; $\mathrm{L}$ large; $\mathrm{M}$ medium; and $\mathrm{S}$ small. In Figure 5(a), several limits have to be specified in order to determine the range of the membership functions. These limits are proportional to the specified design values of displacement $D_{\mathrm{d}}$, velocity $V_{\mathrm{d}}$ and acceleration $A_{\mathrm{d}}$. The notation for these limits are:

$$
\begin{aligned}
& \text { for displacement limit: d_limit1 }=0.2\left(D_{\mathrm{d}}\right) \quad \text { d_limit2 }=0.6\left(D_{\mathrm{d}}\right) \text {; } \\
& \text { for velocity limit: } v_{-} \text {limit } 1=0.2\left(V_{\mathrm{d}}\right) \quad \mathrm{v}_{-} \text {limit } 2=0.6\left(V_{\mathrm{d}}\right) \text {; } \\
& \text { for acceleration limit: a_limit } 1=0.2\left(A_{\mathrm{d}}\right)
\end{aligned}
$$

where the acceleration limit a_limit2 is the most important limit of this controller, and will be discussed in more detail later. In Figures $5(a, b)$, there are two cases of fuzzy logic control: bang_2 logic control (case 1) and fuzzy_2 logic control (case 2). These two controllers are similar 
Input1: relative displacement

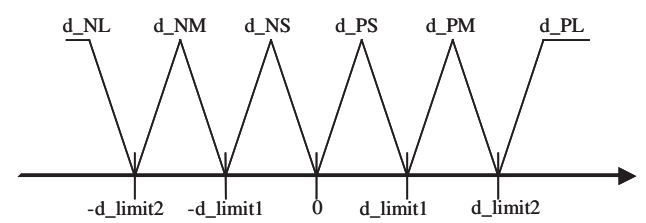

Input2: relative velocity

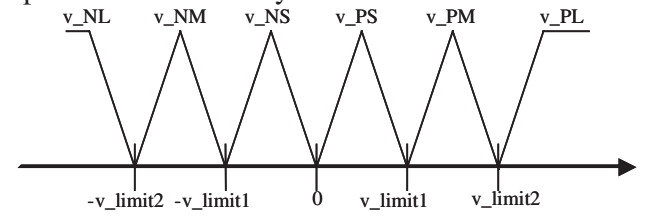

Input3: absolute acceleration

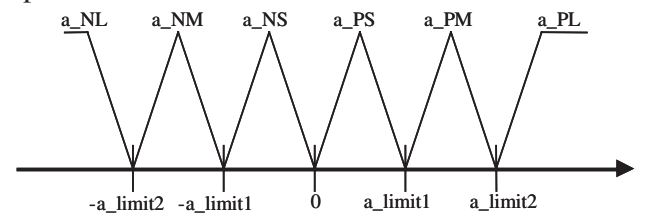

(a)

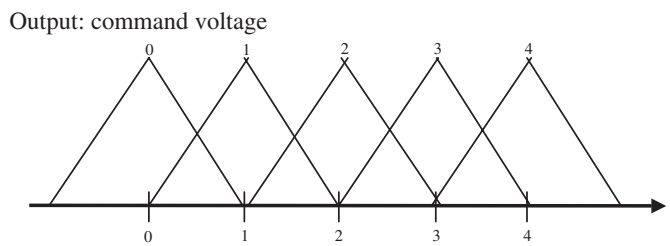

Figure 5. Input membership functions, output command voltage: (a) for case of bang_2; (b) for case of fuzzy_2; The output command voltage for fuzzy 2 case is also shown. (c) output and contro surfaces of fuzzy logic for fuzzy-A and fuzzy-B (with control surfaces).

to each other. The only difference of the two cases is the overlap of the membership functions. The fuzzy_2 (case 2) controller, which shows overlaps in the membership functions, will produce a more smooth output signal than the bang 2 (case-1) controller. In fuzzy logic control, the input signal at each time is changed into linguistic values through a fuzzification interface, so the control performance is not sensitive to the input signal. Because of the characteristic of fuzzy logic control, numerical differentiation and integration can be utilized to reduce the measured signal. For example, in this study, the relative velocity signal is obtained by means of a differential relative displacement signal.

The if-then rules of the fuzzy logic controller (for both bang_2 and fuzzy_2 cases) are specified, as shown in Table IIIa. The indices used in Table IIIa are: a absolute acceleration; $\mathrm{v}$ relative velocity; and $\mathrm{d}$ relative displacement. For example, d_PL means that relative displacement is positive and large, $v_{-}$PS means that relative velocity is positive and small, and 
Input 1: relative displacement
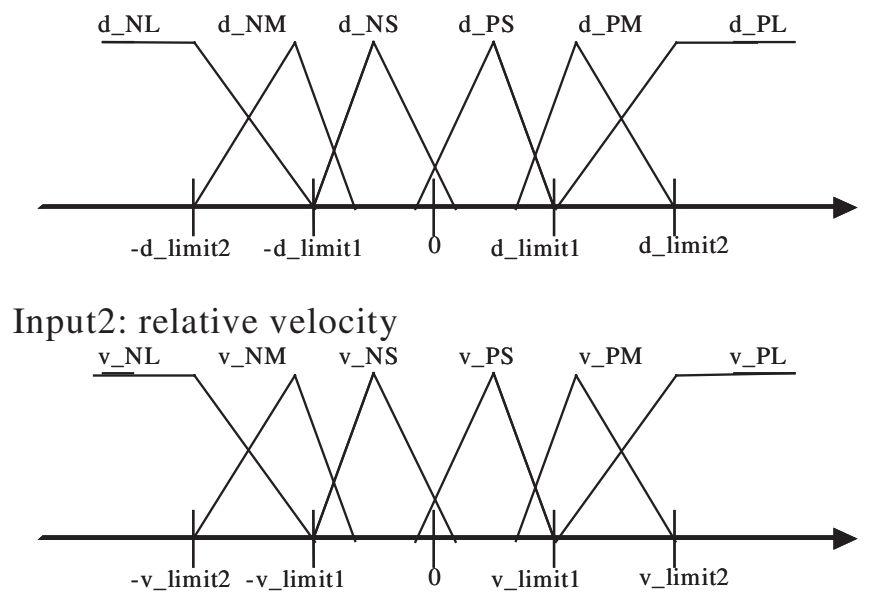

Input3: absolute acceleration

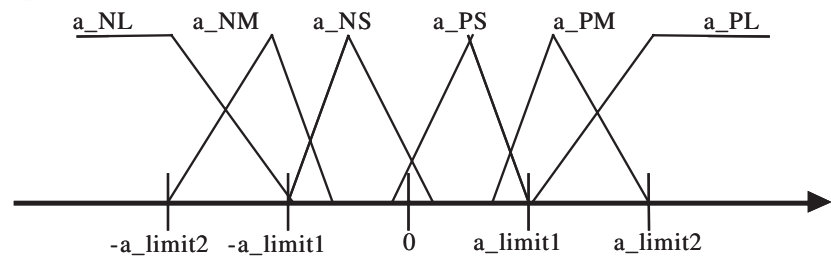

Output: command voltage

(b)

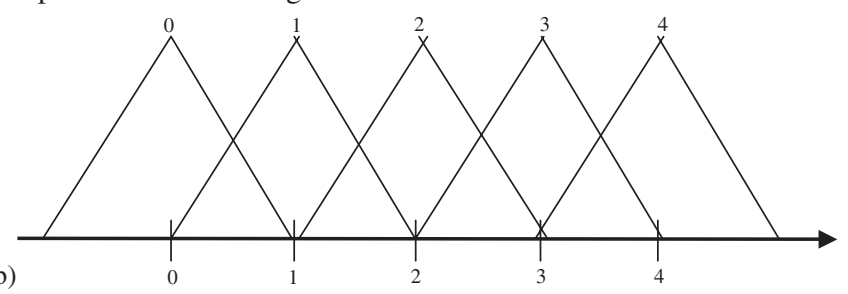

Figure 5. Continued.

a_NM means that absolute acceleration is negative and of middle size, then the output voltage is defined as 2. Table IIIa, shows that the controller usually specifies nonzero voltage to control displacement response, except under the following two conditions: (1) all three kinds of responses (a, v and $\mathrm{d}$ are all small); (2) acceleration response is large (linguistic value is a_PL or $\mathrm{a}_{-} \mathrm{NL}$ ) and acceleration and velocity responses have opposite signs. Condition (1) means that small responses do not need control. Condition (2) means that when acceleration and velocity responses have opposite signs, then by imposing a control force the acceleration response will increase also so that the controller should be specified as zero voltage. The cases for negative 


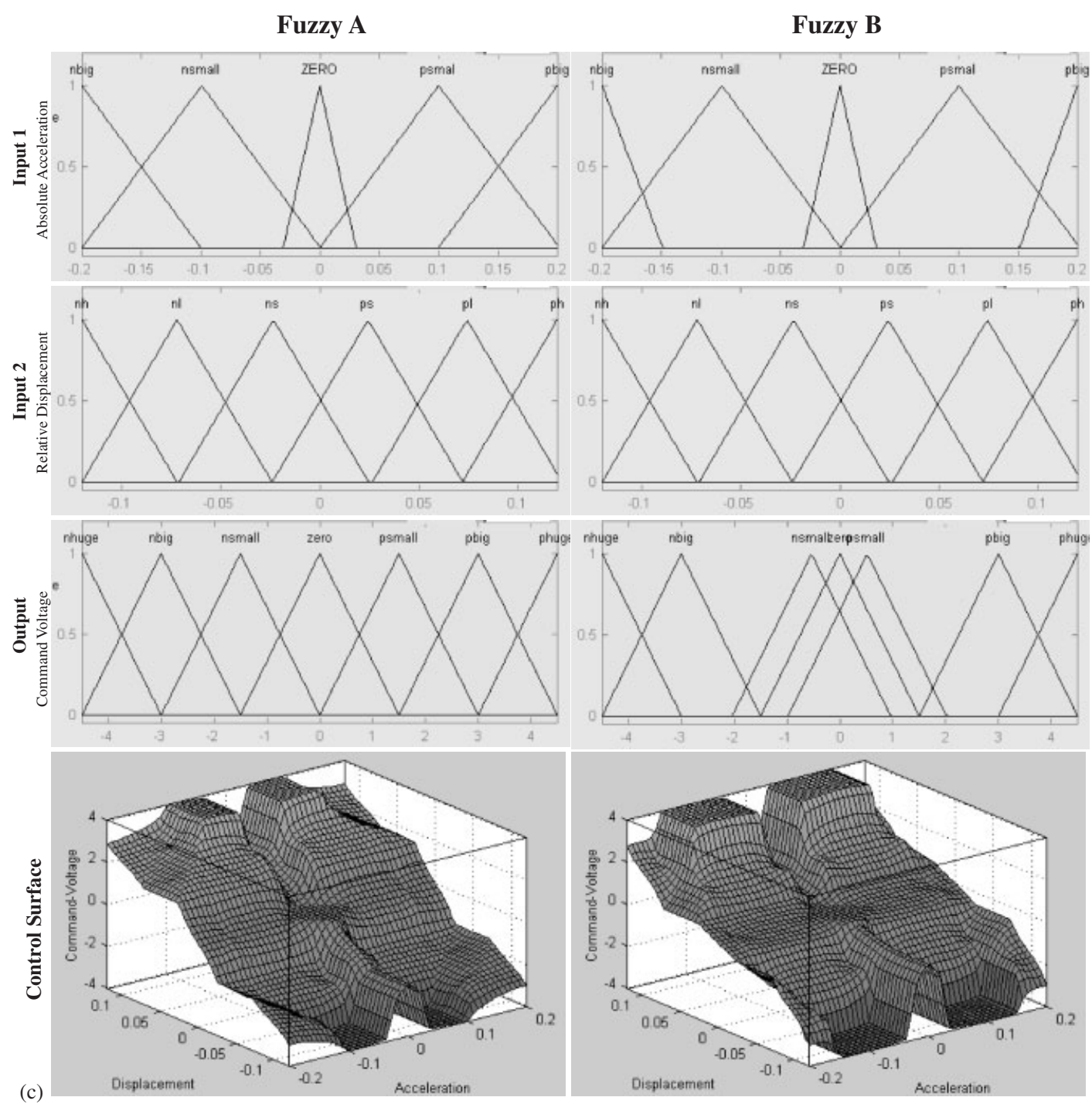

Figure 5. Continued.

displacement are not listed in Table IIIa because when the negative displacement occurs, it is only necessary to change $\mathrm{P}$ to $\mathrm{N}$ and $\mathrm{N}$ to $\mathrm{P}$ so that the table can be utilized in the case of negative displacement.

To improve the reduction of displacement control without increasing the absolute acceleration response, another semi-active controller is developed. Defined as case fuzzy_3 where two feedback signals were used (i.e. relative velocity and absolute acceleration). The feedback signal of relative velocity has only two membership functions, positive and negative, and the membership functions of the absolute acceleration feedback signal are the same as fuzzy_2. The if-then rules are shown in Table IIIb. According to the if-then rules, the 
Table III. (a) If-then rules for control case bang_2 and fuzzy_2. (b) fuzzy_3. (c) fuzzy_A and fuzzy_B.

\begin{tabular}{|c|c|c|c|c|c|c|}
\hline alv & v_PL & v_PM & v__PS & v_NS & v_NM & $\mathrm{v}_{-} \mathrm{NL}$ \\
\hline$a_{-} P L$ & 4 & 4 & 4 & 0 & 0 & 0 \\
\hline$a_{-} P M$ & 4 & 4 & 4 & 2 & 2 & 2 \\
\hline$a_{-} P S$ & 4 & 4 & 4 & 4 & 4 & 4 \\
\hline$a_{-} N S$ & 4 & 4 & 4 & 4 & 4 & 4 \\
\hline a_NM & 2 & 2 & 2 & 4 & 4 & 4 \\
\hline$a \_N L$ & 0 & 0 & 0 & 4 & 4 & 4 \\
\hline
\end{tabular}

d_PM
\begin{tabular}{|c|c|c|c|c|c|c|}
\hline alv & $\mathbf{v}_{-} P L$ & $\mathbf{v} \_P M$ & $\mathbf{v}_{-} P S$ & $\mathbf{v} \_N S$ & $\mathbf{v} \_N M$ & $\mathbf{v}_{-} N L$ \\
\hline$a_{-} P L$ & 3 & 4 & 4 & 0 & 0 & 0 \\
\hline$a_{-} P M$ & 3 & 4 & 4 & 1 & 1 & 1 \\
\hline$a_{-} P S$ & 3 & 4 & 4 & 4 & 4 & 3 \\
\hline$a_{-} N S$ & 3 & 4 & 4 & 4 & 4 & 3 \\
\hline$a_{-} N M$ & 1 & 1 & 1 & 4 & 4 & 3 \\
\hline$a_{-} N L$ & 0 & 0 & 0 & 4 & 4 & 3 \\
\hline
\end{tabular}

\begin{tabular}{|c|c|c|c|c|c|c|}
\hline alv & v_PL & v_PM & $\mathbf{v}_{-} \mathbf{P S}$ & $\mathbf{v}_{-} \mathbf{N S}$ & $\mathbf{v}_{-} \mathbf{N M}$ & v_NL \\
\hline$a_{-} P L$ & 2 & 3 & 4 & 0 & 0 & 0 \\
\hline$a_{-} P M$ & 2 & 3 & 4 & 1 & 1 & 1 \\
\hline$a_{-} P S$ & 2 & 3 & 0 & 0 & 3 & 2 \\
\hline$a_{-} N S$ & 2 & 3 & 0 & 0 & 3 & 2 \\
\hline$a_{-} N M$ & 1 & 1 & 1 & 4 & 3 & 2 \\
\hline$a_{-} N L$ & 0 & 0 & 0 & 4 & 3 & 2 \\
\hline
\end{tabular}

(a)

\begin{tabular}{||c||c|c||}
\hline a $1 \mathrm{v}$ & $\mathbf{v} \_\mathbf{P}$ & $\mathbf{v} \_\mathbf{N}$ \\
\hline \hline $\boldsymbol{a} \_\boldsymbol{P L}$ & 4 & 0 \\
\hline $\boldsymbol{a} \_\boldsymbol{P M}$ & 4 & 1 \\
\hline $\boldsymbol{a} \_\boldsymbol{P S}$ & 4 & 3 \\
\hline $\boldsymbol{a} \_\boldsymbol{N} \boldsymbol{S}$ & 3 & 4 \\
\hline $\boldsymbol{a} \_\boldsymbol{N} \boldsymbol{M}$ & 1 & 4 \\
\hline $\boldsymbol{a} \_\boldsymbol{N L}$ & 0 & 4 \\
\hline \hline
\end{tabular}

(b)

\begin{tabular}{|c|c|c|c|c|c|c|}
\hline \multirow{2}{*}{\multicolumn{2}{|c|}{$\begin{array}{c}\text { Command } \\
\text { Voltage }\end{array}$}} & \multicolumn{5}{|c|}{ Acceleration ( Input $1 / \pm 0.2 \mathrm{~m} / \mathrm{s}^{2}$ ) } \\
\hline & & \multirow{2}{*}{$\begin{array}{l}\text { N-Big } \\
\text { N-Big }\end{array}$} & \multirow{2}{*}{$\begin{array}{l}\text { N-Small } \\
\text { N-Huge }\end{array}$} & \multirow{2}{*}{$\begin{array}{c}\text { Zero } \\
\text { N-Small }\end{array}$} & \multirow{2}{*}{$\begin{array}{l}\text { P-Small } \\
\text { N-Huge }\end{array}$} & \multirow{2}{*}{$\frac{\text { P-Big }}{\text { N-Big }}$} \\
\hline \multirow{6}{*}{ 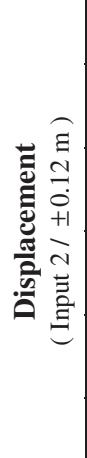 } & N-Huge & & & & & \\
\hline & N-Big & N-Small & N-Huge & N-Small & N-Huge & N-Small \\
\hline & N-Small & N-Small & N-Small & Zero & N-Small & N-Small \\
\hline & P-Small & P-Small & P-Small & Zero & P-Small & P-Small \\
\hline & P-Big & P-Small & P-Huge & P-Small & P-Huge & P-Small \\
\hline & P-Huge & P-Big & P-Huge & P-Small & P-Huge & P-Big \\
\hline
\end{tabular}

characteristics of this case are close to passive-on (the characteristics of fuzzy_2 are close to passive-off), but it will reduce the command voltage in a specified time. Comparing these two cases, fuzzy_2 always uses a small control force to control the absolute acceleration, and a large control force to control the excess displacement; fuzzy_3 always uses a large control force to control the relative displacement, and to reduce the control force when the excess absolute acceleration is occurring. As a result, fuzzy_3 will give a better reduction in relative displacement than fuzzy_2.

Obviously, the effectiveness of the controller depends on how to specify the acceleration limit a_limit2. If the control purpose is focused on the control of larger structural acceleration response or structural response close to the design value $A_{\mathrm{d}}$, a_limit2 value should be larger, such 
as $0.6 A_{\mathrm{d}}-0.8 A_{\mathrm{d}}$. On the contrary, the a_limit 2 value should be smaller, such as $0.2 A_{\mathrm{d}}-0.3 A_{\mathrm{d}}$. To control all ranges of structure response, the a_limit2 value should be changed at the appropriate time. In this study, the a_limit2 value is specified so as to focus on smaller structure responses first. When the structure response is larger than a certain level, the a_limit2 value is changed to larger value in order to control the increased structure response. When the disturbance is over, a_limit2 is returned to the smaller value until the next disturbance. The appropriate value of the a_limit2 can be obtained by trial and error, and will be discussed later.

In addition to the control cases illustrated above, two additional fuzzy logical controllers (fuzzy A and fuzzy B) are used in this study for comparison. Two feedback signals (absolute acceleration and relative displacement) are used in these two cases. The design concept of $t$ hese two cases is to reduce absolute acceleration and relative displacement at the same time. When the absolute acceleration is small, the command voltage will increase rapidly with the displacement. When the absolute acceleration is big, the command voltage will increase slowly with the displacement. The membership functions of input and output are shown in Figure 5(c). The only difference between these two cases is the arrangement of the membership functions of output signal; fuzzy $\mathrm{B}$ has a more gradual slope with respect to relative displacement and leads to a better reduction ratio for the absolute acceleration responses. In addition, the relative control surfaces are also shown in this figure and the if-then rules for these two control strategies are listed in Table IIIc. A band with small to zero command voltage is designed to ensure that no residual command exists when the excitation is over.

\subsection{Determining a_limit2 and the number of $M R$ dampers}

By means of the fuzzy logic controller, the correct trend of output command voltage can be obtained. But this command voltage must be converted to the control force and the control performance evaluated. With the specified RD-1005-3 $3 \mathrm{kN}$ MR damper a limited value of the maximum restoring force can be provided with a specified voltage. If the excitation level is significantly large and the single damper can not provide enough restoring force for the control system, it is necessary to use more dampers to control the system. In order to find the best control effectiveness, the a_limit2 value and the number of MR dampers have to be determined. Set a ratio $\beta$ which is defined as the ratio of the required control force provided by dampers to the design forces:

$$
\beta=\frac{N_{\mathrm{MR}} \times F_{\mathrm{MR}}}{\left(\text { Design } \_\mathrm{a}\right) \times M}=\frac{\text { force }_{\text {control }}}{\text { force }_{\text {design }}}
$$

where $F_{\mathrm{MR}}$ is the maximum force that a single MR damper can provide, and $N_{\mathrm{MR}}$ is the number of MR dampers. $M$ is the mass of the super structure, Design a is the design acceleration. The required control force can be provided by the number of MR dampers, $N_{\mathrm{MR}}$, and the maximum force that a single MR damper can provide is $F_{\mathrm{MR}}$.

To examine the control effectiveness of the system for different excitation levels of $\beta$ must be determined first. Large values of $\beta$ indicate that large control forces will be supplied to the structural system and the displacement control response is good, but acceleration control response is poor. For each soil type, let $\beta=0,0.1,0.2, \ldots, 1.0$, respectively, and set a_limit2 = $0.2 A_{\mathrm{d}}$ and $0.3 A_{\mathrm{d}}$ for small structure response, and set a_limit2 $=0.6 A_{\mathrm{d}}, 0.7 A_{\mathrm{d}}$ and $0.8 A_{\mathrm{d}}$ for large structure response. Through numerical simulation, the response ratio (defined as the ratio 

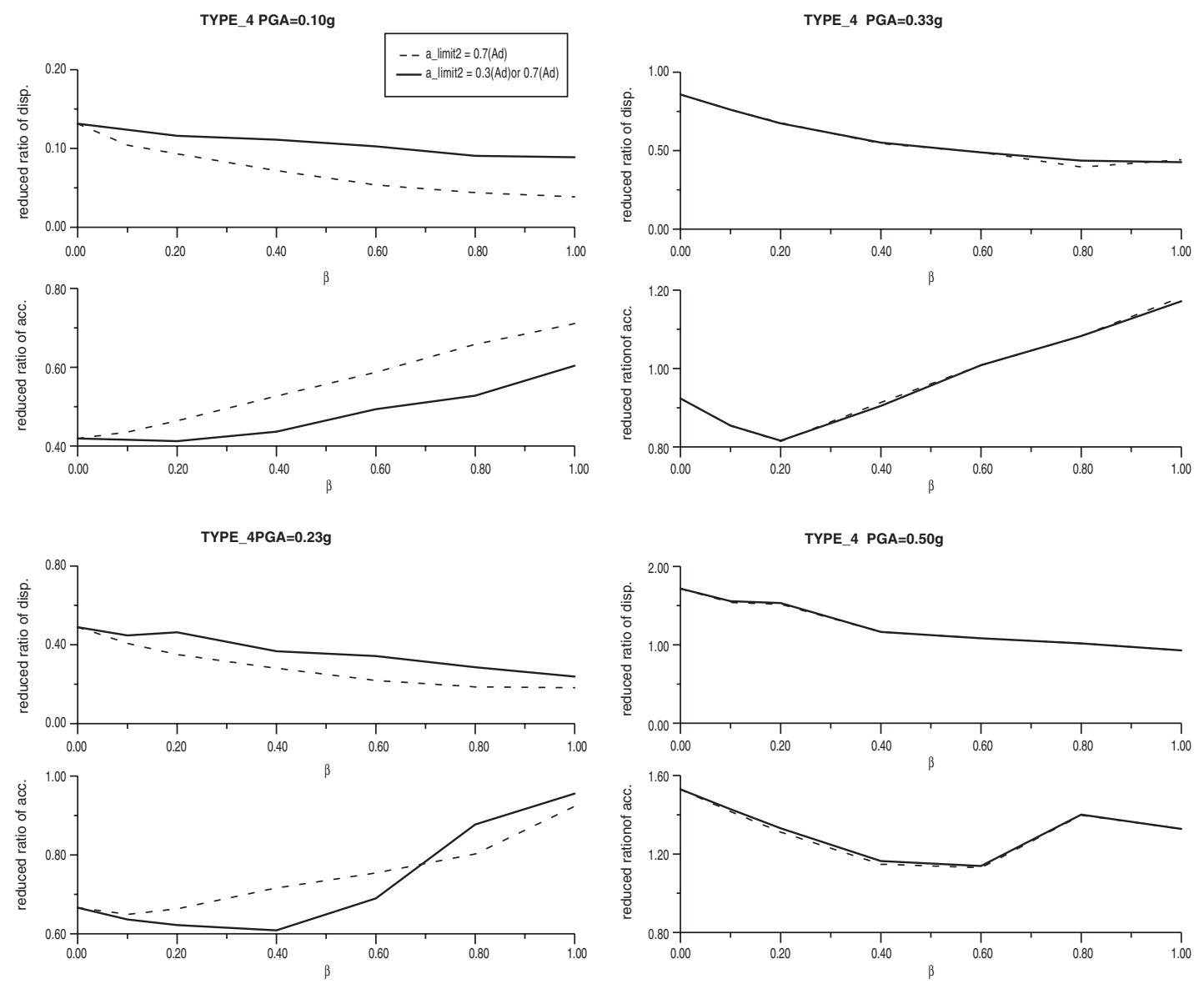

Figure 6. Plot of reduced response ratio with respect to $\beta$ for two different cases a_limit2 $=0.3 A_{\mathrm{d}}$ (solid line) and $0.7 A_{\mathrm{d}}$ (dashed line); four levels of input ground motion excitations were studied.

of system response with and without control) of every case can be examined for each design ground excitation. For example, in soil conditions of type 4, a_limit2 is set to $0.3 A_{\mathrm{d}}$ for small structural response and $0.7 A_{\mathrm{d}}$ for large structural response, and response ratios varying with $\beta$ are plotted in Figure 6. In this figure, for small excitation levels the displacement response ratio decreases with the increasing $\beta$ and the acceleration response ratio increase, because during a small earthquake excitation the acceleration response is smaller than a_limit2 and the commend voltage (set to zero) is not yet activated. But for large excitation levels the acceleration response ratio will decrease with increasing $\beta$ value in the beginning. When $\beta$ value reaches to 0.2 or 0.4 the acceleration response will begin to increase with increasing $\beta$ value. An appropriate value of $\beta$ can be determined with a specified a_limit2. Through this analysis $\beta=0.4$ is determined for a_limit $2=0.3 A_{\mathrm{d}}$ and $0.7 A_{\mathrm{d}}$ for type 4 soil conditions. These results are good choices to obtain optimum control effectiveness under the design ground excitation. Table IV shows the estimated value of $\beta$ for different control schemes and design accelerations. 
Table IV. Comparison of peak response (unit of displacement $\mathrm{m}$ ) of a single-degree-of-freedom isolated system for six different types of control method (bang_2 is semi-active control); six different input ground motions were examined.

\begin{tabular}{|c|c|c|c|c|c|c|}
\hline & \multicolumn{5}{|c|}{ TYPE_1 } \\
\hline PGA & $0.1 \mathrm{~g}$ & & $0.33 \mathrm{~g}$ & & $0.5 \mathrm{~g}$ & \\
\hline & $\max \mathrm{d}$ & $\max \mathrm{a}$ & $\max \mathrm{d}$ & $\max \mathrm{a}$ & $\max \mathrm{d}$ & $\max \mathrm{a}$ \\
\hline un-control & 0.0167 & 0.3139 & 0.0930 & 0.6559 & 0.1862 & 1.0775 \\
\hline passive-off & 0.0166 & 0.3177 & 0.0889 & 0.6452 & 0.1779 & 1.0557 \\
\hline passive-on & 0.0086 & 0.4822 & 0.0554 & 0.7923 & 0.1040 & 0.9623 \\
\hline bang_2 & $\mathbf{0 . 0 1 6 6}$ & $\mathbf{0 . 3 1 9 9}$ & $\mathbf{0 . 0 7 0 3}$ & $\mathbf{0 . 5 6 2 3}$ & $\mathbf{0 . 1 3 5 4}$ & $\mathbf{0 . 8 6 4 7}$ \\
\hline viscous & 0.0155 & 0.3392 & 0.0660 & 0.6522 & 0.1319 & 0.9923 \\
\hline
\end{tabular}

\begin{tabular}{|c|c|c|c|c|c|c|c|c|}
\hline excitation & \multicolumn{7}{|c|}{ TYPE_4 } \\
\hline PGA & $0.10 \mathrm{~g}$ & & $0.23 \mathrm{~g}$ & & $0.33 \mathrm{~g}$ & & $0.5 \mathrm{~g}$ & \\
\hline & $\max \mathrm{d}$ & $\max \mathrm{a}$ & $\max \mathrm{d}$ & $\max \mathrm{a}$ & $\max \mathrm{d}$ & $\max \mathrm{a}$ & $\max d$ & $\max \mathrm{a}$ \\
\hline un-control & 0.0416 & 0.8376 & 0.1548 & 1.3300 & 0.2714 & 1.8448 & 0.5428 & 3.0552 \\
\hline passive-off & 0.0379 & 0.8384 & 0.1384 & 1.3010 & 0.2457 & 1.7728 & 0.4823 & 2.8581 \\
\hline passive-on & 0.0066 & 1.0948 & 0.0378 & 1.5072 & 0.1052 & 1.9238 & 0.2896 & 2.7300 \\
\hline bang_2 & $\mathbf{0 . 0 3 5 2}$ & $\mathbf{0 . 8 7 2 0}$ & $\mathbf{0 . 1 1 6 0}$ & $\mathbf{1 . 2 1 5 3}$ & $\mathbf{0 . 1 7 4 2}$ & $\mathbf{1 . 8 0 7 3}$ & $\mathbf{0 . 3 6 8 1}$ & $\mathbf{2 . 3 2 5 4}$ \\
\hline viscous & 0.0321 & 0.8381 & 0.1157 & 1.3054 & 0.2027 & 1.7521 & 0.3822 & 2.7419 \\
\hline
\end{tabular}

\begin{tabular}{|c|c|c|c|c|c|c|}
\hline Excitation & \multicolumn{5}{|c|}{ KAU085 } \\
\hline PGA & $0.1 \mathrm{~g}$ & & $0.33 \mathrm{~g}$ & & $0.5 \mathrm{~g}$ & \\
\hline & $\max \mathrm{d}$ & $\max \mathrm{a}$ & $\max \mathrm{d}$ & $\max \mathrm{a}$ & $\max \mathrm{d}$ & $\max \mathrm{a}$ \\
\hline un-control & 0.0070 & 0.2680 & 0.0293 & 0.3960 & 0.0486 & 0.5020 \\
\hline passive-off & 0.0066 & 0.2750 & 0.0286 & 0.4040 & 0.0479 & 0.5150 \\
\hline passive-on & 0.0101 & 0.5230 & 0.0224 & 0.6060 & 0.0360 & 0.7270 \\
\hline bang_2 & $\mathbf{0 . 0 0 7 1}$ & $\mathbf{0 . 2 8 1 0}$ & $\mathbf{0 . 0 2 8 5}$ & $\mathbf{0 . 4 0 4 0}$ & $\mathbf{0 . 0 4 7 0}$ & $\mathbf{0 . 5 1 2 0}$ \\
\hline viscous & 0.0059 & 0.3190 & 0.0257 & 0.4560 & 0.0436 & 0.6070 \\
\hline
\end{tabular}

\begin{tabular}{|c|c|c|c|c|c|c|c|c|}
\hline excitation & \multicolumn{7}{|c|}{ TAP010 } \\
\hline PGA & $0.10 \mathrm{~g}$ & & $0.23 \mathrm{~g}$ & & $0.33 \mathrm{~g}$ & & $0.5 \mathrm{~g}$ & \\
\hline & $\max \mathrm{d}$ & $\max \mathrm{a}$ & $\max \mathrm{d}$ & $\max \mathrm{a}$ & $\max \mathrm{d}$ & $\max \mathrm{a}$ & $\max \mathrm{d}$ & $\max \mathrm{a}$ \\
\hline un-control & 0.0371 & 0.8195 & 0.1790 & 1.4481 & 0.2995 & 1.9933 & 0.4892 & 2.8524 \\
\hline passive-off & 0.0351 & 0.8293 & 0.1669 & 1.4412 & 0.2796 & 1.9737 & 0.4558 & 2.8259 \\
\hline passive-on & 0.0054 & 0.9816 & 0.0476 & 1.6672 & 0.1167 & 1.9819 & 0.3188 & 2.8871 \\
\hline bang_2 & $\mathbf{0 . 0 3 8 1}$ & $\mathbf{0 . 8 4 1 9}$ & $\mathbf{0 . 1 6 3 7}$ & $\mathbf{1 . 5 8 2 6}$ & $\mathbf{0 . 2 5 5 0}$ & $\mathbf{1 . 8 6 5 8}$ & $\mathbf{0 . 3 8 6 7}$ & $\mathbf{2 . 5 1 6 1}$ \\
\hline viscous & 0.0323 & 0.8457 & 0.1471 & 1.4479 & 0.2447 & 1.9973 & 0.3980 & 2.8642 \\
\hline
\end{tabular}

\begin{tabular}{|c|c|c|c|c|c|c|}
\hline excitation & \multicolumn{5}{|c|}{ CHY106 } \\
\hline PGA & $0.1 \mathrm{~g}$ & & $0.33 \mathrm{~g}$ & & $0.5 \mathrm{~g}$ & \\
\hline & $\max \mathrm{d}$ & $\max \mathrm{a}$ & $\max \mathrm{d}$ & $\operatorname{max~a}$ & $\operatorname{max~d}$ & $\max \mathrm{a}$ \\
\hline un-control & 0.0063 & 0.2652 & 0.0203 & 0.3349 & 0.0310 & 0.3841 \\
\hline Passive-off & 0.0059 & 0.2663 & 0.0202 & 0.3405 & 0.0305 & 0.3906 \\
\hline Passive-on & 0.0036 & 0.4603 & 0.0094 & 0.5255 & 0.0203 & 0.5923 \\
\hline bang_2 & $\mathbf{0 . 0 0 5 9}$ & $\mathbf{0 . 2 6 7 4}$ & $\mathbf{0 . 0 1 8 3}$ & $\mathbf{0 . 3 3 1 6}$ & $\mathbf{0 . 0 2 7 0}$ & $\mathbf{0 . 3 8 7 4}$ \\
\hline viscous & 0.0048 & 0.2746 & 0.0190 & 0.3812 & 0.0270 & 0.4384 \\
\hline
\end{tabular}

\begin{tabular}{|c|c|c|c|c|c|c|c|c|}
\hline excitation & \multicolumn{7}{|c|}{ TAP016 } \\
\hline PGA & $0.10 \mathrm{~g}$ & & $0.23 \mathrm{~g}$ & & $0.33 \mathrm{~g}$ & & $0.5 \mathrm{~g}$ & \\
\hline & $\max \mathrm{d}$ & $\operatorname{max~a}$ & $\max \mathrm{d}$ & $\max \mathrm{a}$ & $\max \mathrm{d}$ & $\max \mathrm{a}$ & $\max \mathrm{d}$ & $\max \mathrm{a}$ \\
\hline un-control & 0.0691 & 0.9558 & 0.1454 & 1.3095 & 0.1972 & 1.5414 & 0.2872 & 1.9231 \\
\hline passive-off & 0.0663 & 0.9618 & 0.1404 & 1.3408 & 0.1883 & 1.5713 & 0.2691 & 1.9693 \\
\hline passive-on & 0.0072 & 1.1340 & 0.0867 & 1.8240 & 0.1646 & 2.2011 & 0.2901 & 2.7744 \\
\hline bang_2 & $\mathbf{0 . 0 6 0 1}$ & $\mathbf{0 . 9 3 4 1}$ & $\mathbf{0 . 1 4 4 8}$ & $\mathbf{1 . 3 2 2 0}$ & $\mathbf{0 . 1 8 7 3}$ & $\mathbf{1 . 7 9 2 4}$ & $\mathbf{0 . 2 8 6 6}$ & $\mathbf{2 . 0 5 2 1}$ \\
\hline viscous & 0.0615 & 0.9744 & 0.1305 & 1.4191 & 0.1729 & 1.7013 & 0.2484 & 2.1823 \\
\hline
\end{tabular}

Note: "max d": maximum displacement, "max a": maximum acceleration.

\subsection{Results of numerical simulation}

Six different types of ground motion were selected as input motions (Figure 7: site-1, KAU, and CHY hard site condition, site-4, TAP soft site conditions with a basin effect). The input 
TYPE_1 : obtained by performing spectrum compatible time analysis

\section{KAU085 : recorded at $4 / 25 / 95$ 8:28:51 \\ CHY106 : recorded at $10 / 31 / 95$ 22:26:52}
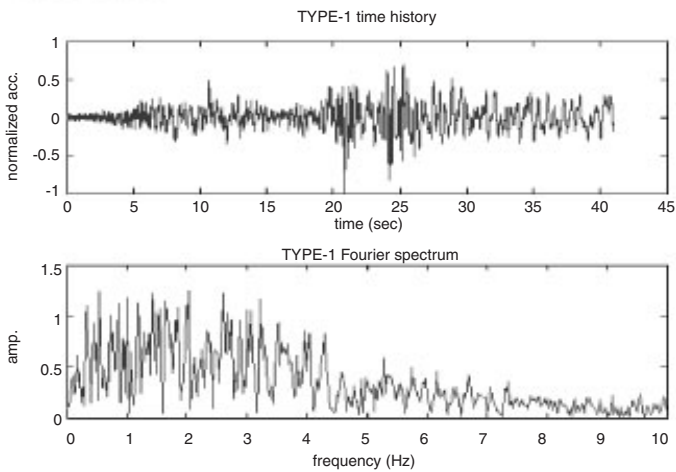

TYPE_ 4 : obtained by performing spectrum compatible time history analysis

TAP010 : recorded at $2 / 23 / 95$ 5:19:10

TAP016 : recorded at $3 / 29 / 96$ 3:29:32
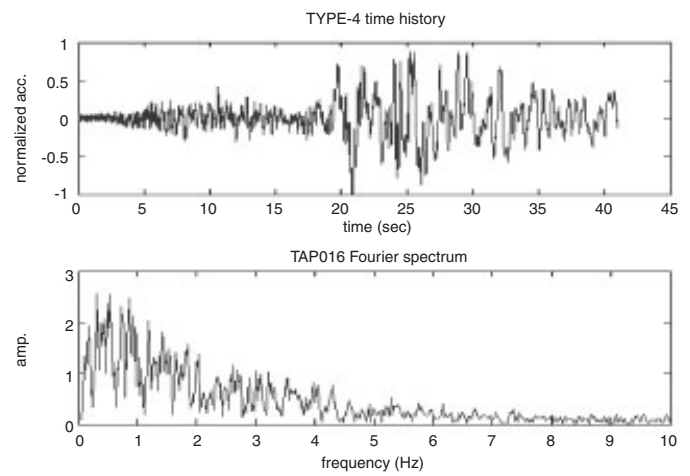

Figure 7. Six ground motions as input motion for numerical study.
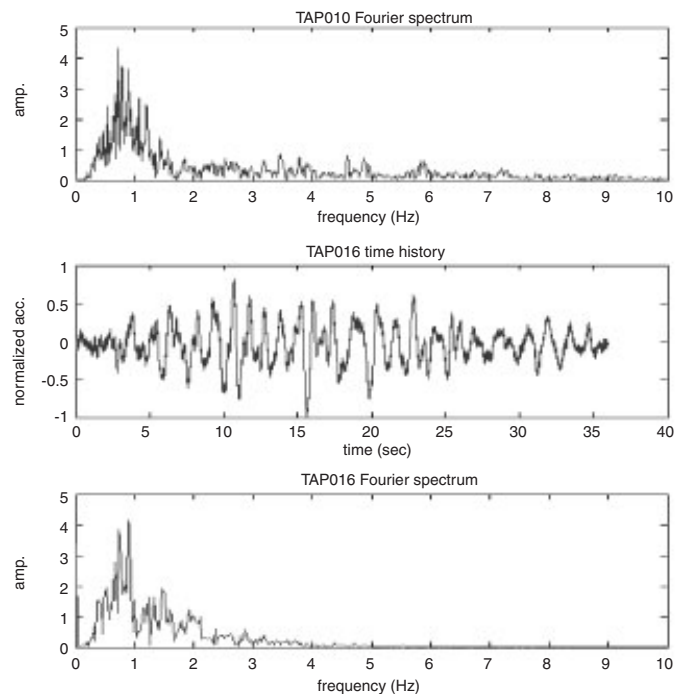

J. Struct. Control 2003; 10:77-100 
Table V. Peak displacement response from numerical simulation of a two-degrees-of-freedom isolated bridge; units; displacement $(\mathrm{m})$, force $(\mathrm{kN})$.

\begin{tabular}{lcc}
\hline PGA & \multicolumn{2}{c}{$0.33 g$} \\
\cline { 2 - 3 } Excitation & \multicolumn{2}{c}{ Type 1 } \\
\cline { 2 - 3 } & \multicolumn{2}{c}{ Maximum relative displacement } \\
\hline Uncontrolled & 0.093 & Maximum base shear \\
Passive-off & 0.0889 & 1732.4684 \\
Passive-on & 0.0499 & 1701.1526 \\
bang_2 & 0.0663 & 1930.4544 \\
fuzzy_2 & 0.0809 & 1480.0652 \\
bang_3 & 0.0646 & 1652.2228 \\
fuzzy_3 & 0.0633 & 1532.2894 \\
Viscous damper & 0.0673 & 1531.3104 \\
fuzzy A & 0.0627 & 1729.9383 \\
fuzzy B & 0.0715 & 1636.9337 \\
\hline
\end{tabular}
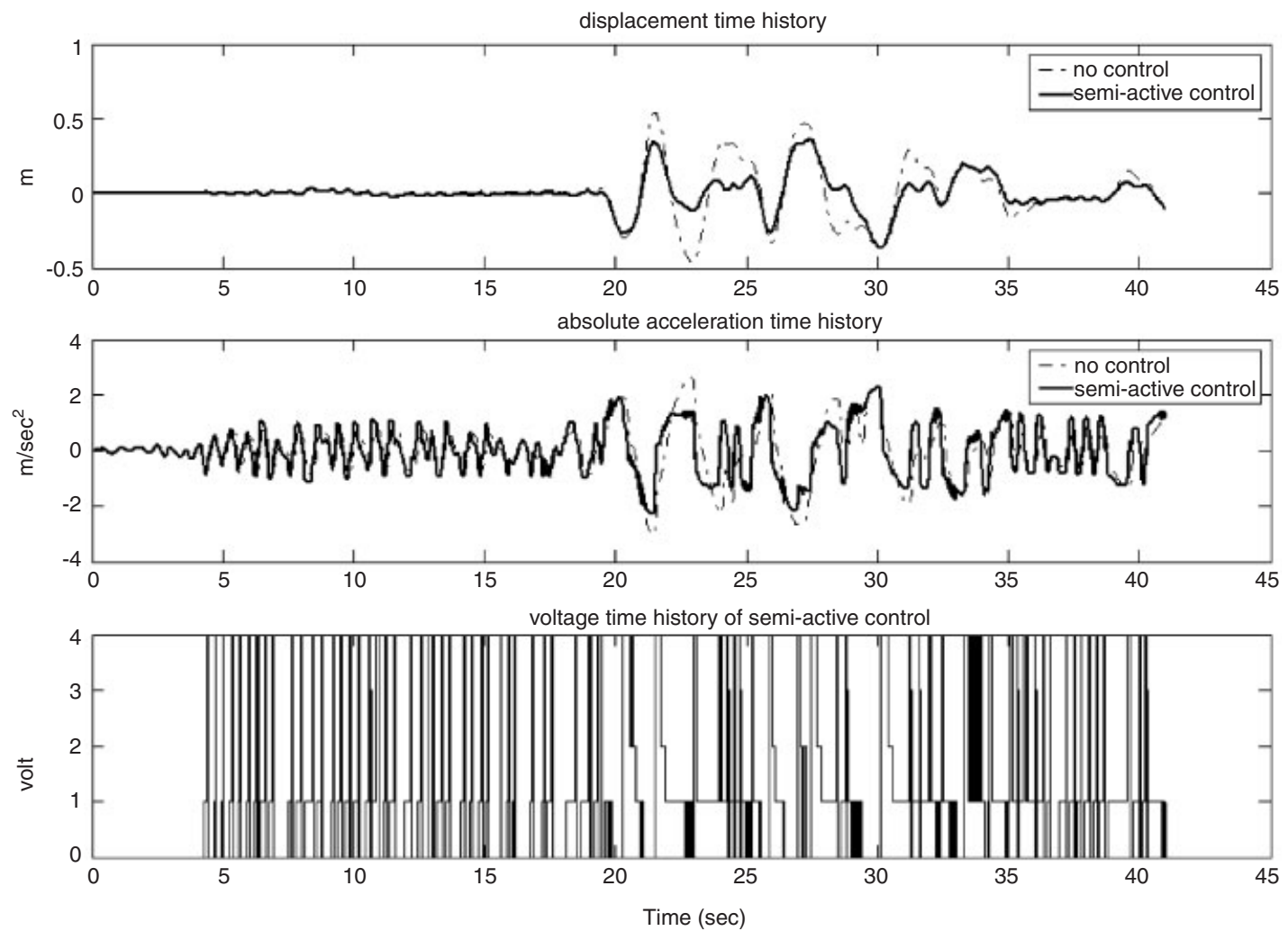

Figure 8. Comparison of the time-history response (displacement and acceleration) between uncontrolled and semi-active controlled SDOF isolation system subjected to Type 4 design excitation with $\mathrm{PGA}=0.5 \mathrm{~g}$ soil type 4; the control voltage of the system is also shown. 
time-history and its Fourier amplitude are shown in Figures 7(a,b). Peak responses from numerical simulation are summarized in Table V. In the case of passive-off control, the restoring force of the MR damper is very small, so that the performance of passive-off control is like that of an un controlled system. On the contrary, the restoring force of the MR damper is large in the passive-on case, so it can reduce the relative displacement response of the isolation system well, but the absolute acceleration response will increase. For semi-active control (using bang_2), the peak acceleration response was close to that of the real uncontrolled case, but the peak displacement response was smaller than for the uncontrolled case. It can be seen that semi-active control is useful to reduce displacement response without increasing absolute acceleration responses of base-isolated systems. Comparison on the time-history response (displacement and acceleration) between the uncontrolled case and the case of using semi-active control of the SDOF isolation system when subjected to type 4 design excitation with PGA $=0.5 \mathrm{~g}$ of soil type 4 is shown in Figure 8. The control voltage of the semi-active control system is also shown in Figure 8.

In order to compare semi-active control using MR-damper with passive-on, passive-off and passive control (using a viscous damper), another example was studied. The type 1 ground motion normalized to $\mathrm{PGA}=0.50 \mathrm{~g}$ was used as input motion. Comparison of the control effectiveness was also studied and is shown in Figure 9. The case of passive-off means that the
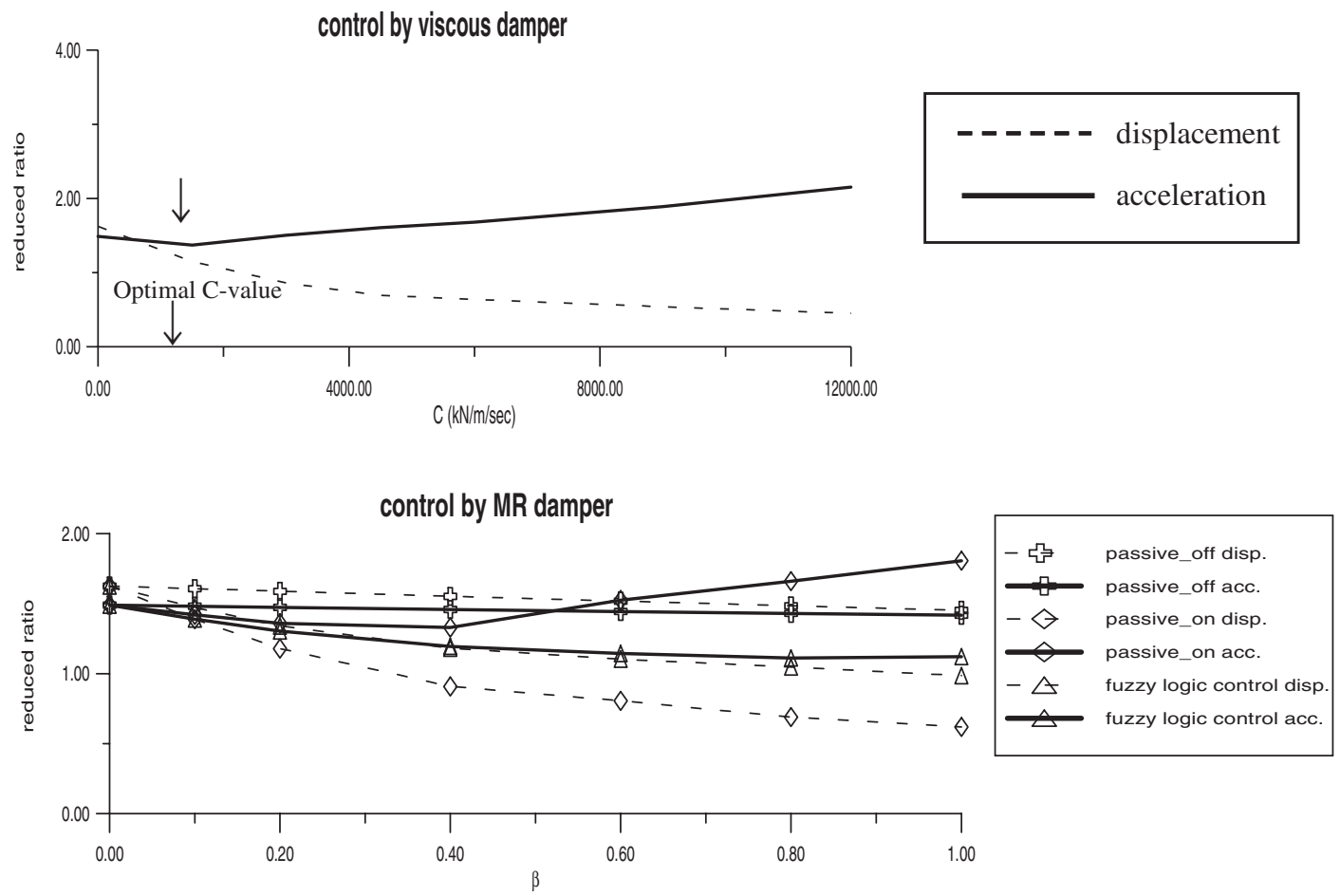

Figure 9. Using type 1 site condition ground motion and scaling PGA to $0.50 \mathrm{~g}$ as input motion to determine the optimal damping value of viscous damper, comparing the response with different control algorithms: (a) plot of displacement and acceleration response ratio for system with and without viscous damper for control of SDOF system; (b) comparison of the displacement and acceleration response ratio for different control algorithms. 


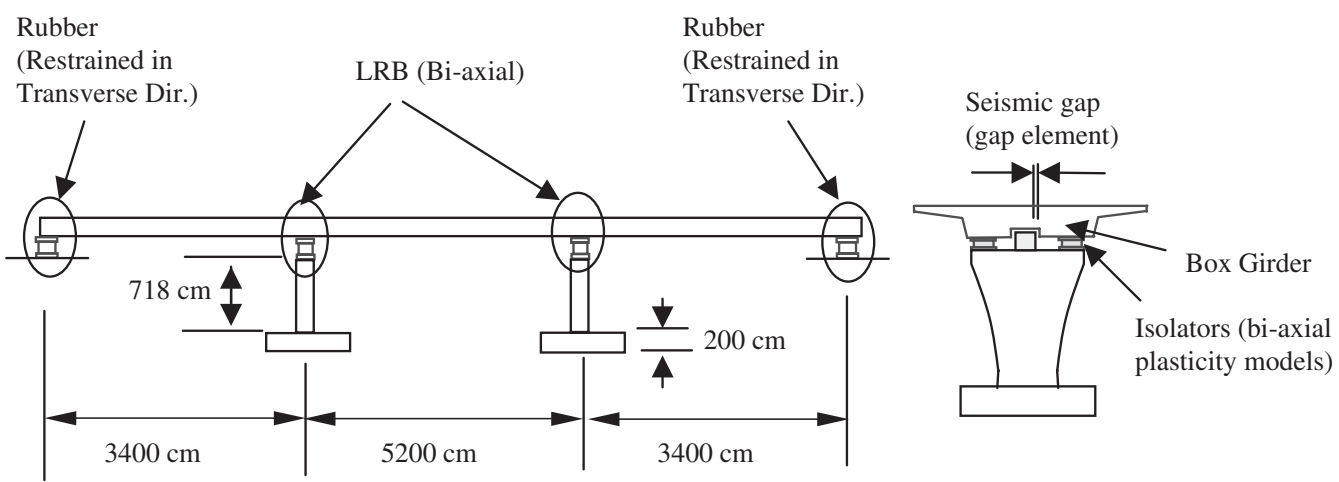

Figure 10. The elevation and lateral view of an isolated bridge.

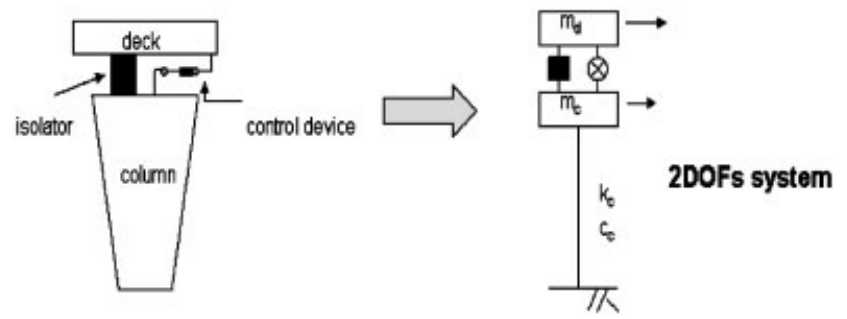

Figure 11. A two-degree-of-freedom system to simulate a bridge column and deck with an isolation system.

voltage for the MR damper is set to zero, and the case of passive-on means the voltage for MR damper is set to $(\mathrm{V}=4.0 \mathrm{~V})$. For viscous damper control it is assumed that the system with viscous damping only was added to the system in the simulation study. Figure 9 shows the different damping values of $C\left(\mathrm{kN} / \mathrm{m} / \mathrm{s}^{-1}\right)$ for a viscous damper with respect to the response ratio (system with control divided by system without control). It is found that by increasing the damping value provided by the viscous damper the displacement of the system will decrease and the acceleration will decrease a little, but when damping value reaches to a certain value (i.e. $1500 \mathrm{kN} / \mathrm{m} / \mathrm{s}^{-1}$ ) the acceleration response will begin to increase. In this study we select $C=1500 \mathrm{kN} / \mathrm{m} / \mathrm{s}^{-1}$ as the optimal value for system control with a viscous damper. This study shows that, for the case of passive-on, one can achieve reduction of displacement very well, but for control the acceleration response is very poor. Semi-active control with the MR damper provides good control efficiency between passive-on and passive-off.

\section{APPLICATION OF SEMI-ACTIVE CONTROL TO AN ISOLATED BRIDGE}

In this study, an isolated bridge in Taiwan was utilized to investigate the application of semiactive control devices to control an isolated bridge structure. The elevation and lateral view of

Figure 12. Time-history response of base shear and relative displacement of a two-degrees-of-freedom isolated bridge for different control methods: (a) viscous damper; (b) passive-off; (c) passive-on; and (d) fuzzy-3. The command voltage and the force exerted by MR damper are also shown. 
TYPE_1 PGA=0.33g

Viscous damper
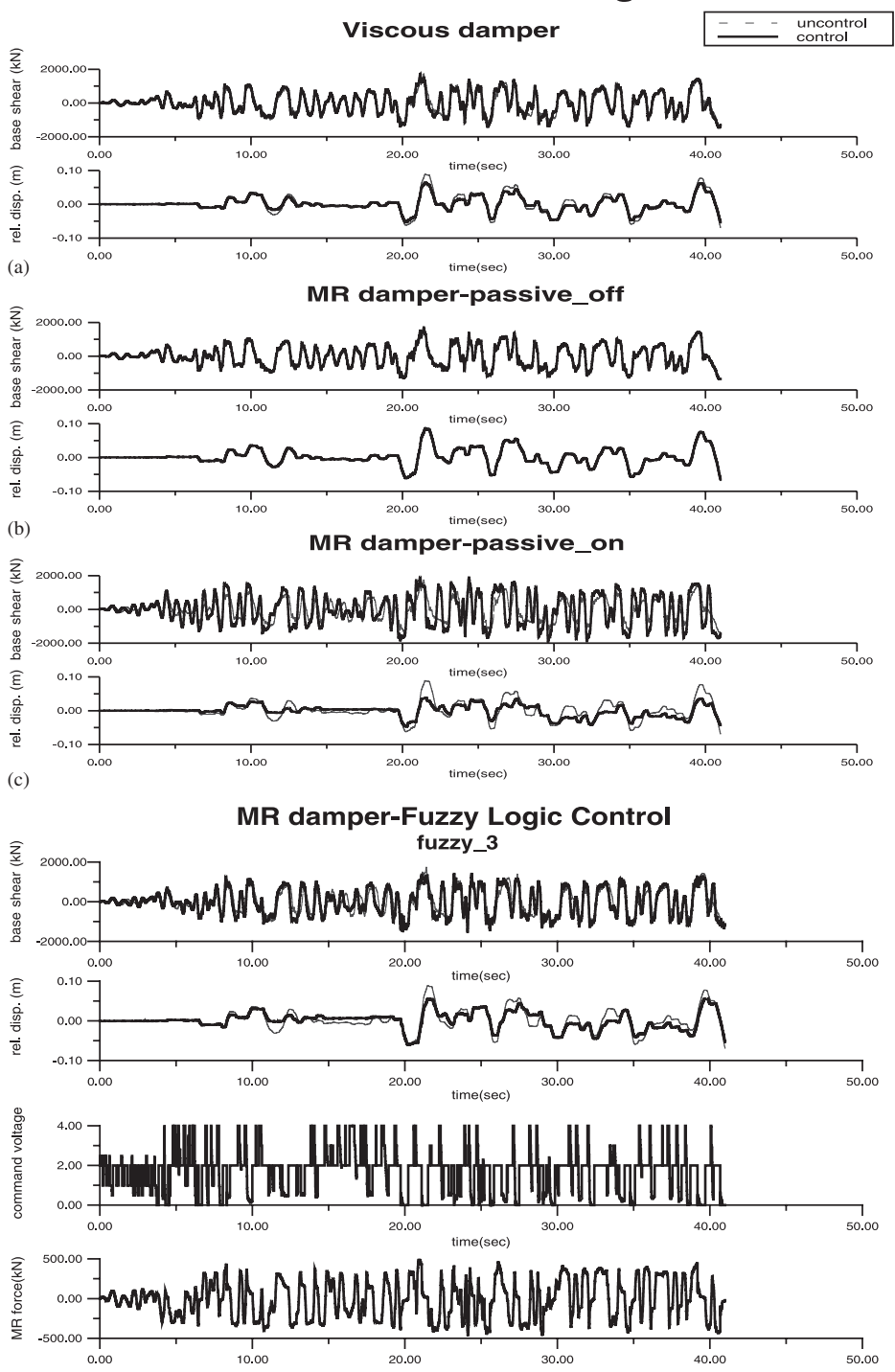

(d)

time(sec)
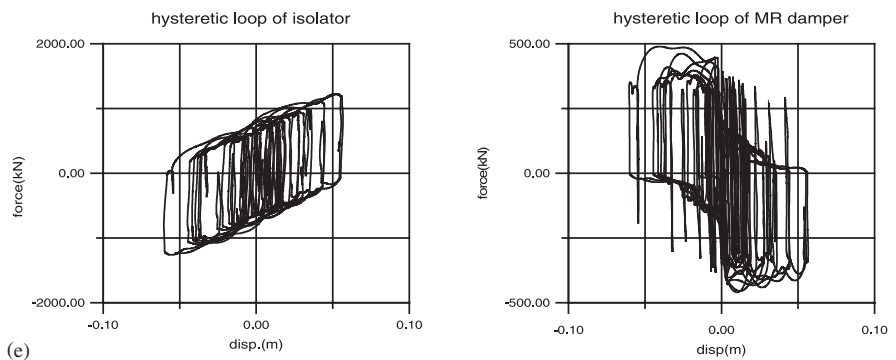
this isolated bridge is shown in Figure 10. For study of control effectiveness the bridge was simplified to a two-degree-of-freedom isolation system, as shown in Figure 11. The bridge deck was lumped with deck mass $m_{\mathrm{d}}=2400$ ton, the bridge pier was also lumped with pier mass $m_{\mathrm{c}}$ $=115.5$ ton, and the bridge system is specified as a system with two lumped masses. The stiffness and damping ratio of bridge pier are specified as $k_{\mathrm{c}}=320000 \mathrm{kNm}$ and $\xi_{\mathrm{c}}=3 \%$, respectively. The same ground excitations (soil type 1) mentioned in the previous example were used as input motion, but with the PGA level of ground excitation normalized to the design level, i.e. $\mathrm{PGA}=0.33 \mathrm{~g}$. Peak responses from numerical simulation are summarized in Table $\mathrm{V}$. In this table, the effectiveness of different semi-active control cases is also shown. Control of the isolated bridge by a semi-active control strategy will reduce the relative displacement response between deck and column without increasing the base shear force. On the basis of the proposed three control strategies, fuzzy-3, fuzzy-A and fuzzy-B, the control effectiveness of the bridge is

TYPE_1 PGA $=0.33 \mathrm{~g}$
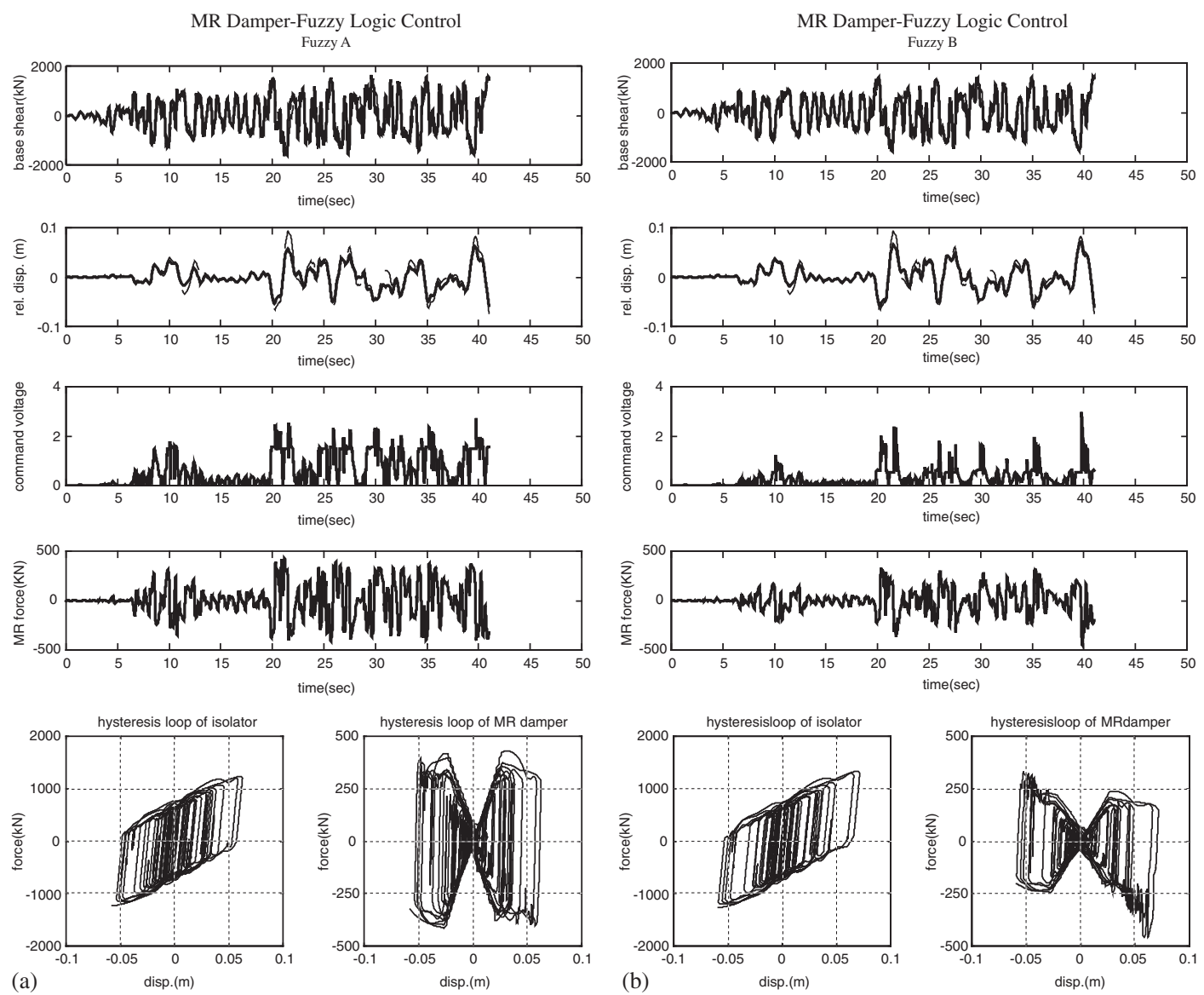

Figure 13. Time-history responses of base shear, relative displacement, command voltage and forces exerted by an MR damper for an isolated bridge for different control methods: (a) fuzzy-A; (b) fuzzy-B. 
examined. Time-history responses of the bridge structure, including base shear, relative displacement, commend voltage of the MR damper and forces exerted by damper on the isolated bridge, subjected to type 1 ground excitation with design PGA value of $0.33 \mathrm{~g}$, are showed in Figure 12. The time-history responses of the bridge structure with control systems (viscous damper versus uncontrolled system; semi-active MR damper versus passive-off system; or semi-active MR damper versus passive-on system) and the hysteretic loops (both MR damper and the isolator) are also shown. The fuzzy-3 controller was used for semi-active control. Figure 13 shows the time-history responses of base shear, relative displacement, command voltage of the MR damper and forces exerted by the damper of the isolated bridge, with either fuzzy-A or using fuzzy-B control are shown. The restoring force diagram of the isolator and the MR damper is also shown. According to these figures, the semi-active control system can reduce the relative displacement between bridge deck and pier quite effectively.

\section{CONCLUSIONS}

In this study, a Bouc-Wen hysteretic voltage-dependent model was developed from performance tests of a $3 \mathrm{kN}$ MR damper. It provides a numerical model of MR damper for experimental verification. By validation analysis, this numerical model is accurate enough to modify the behavior of MR damper.

Based on the developed MR damper, a series of numerical simulation were conducted to develop the effective controller for this type of semi-active control system. The if-then rules for a fuzzy logic controller were developed for the control of an isolated bridge system to reduce the relative displacement between bridge deck and pier. Generally when using passive control systems, such as viscous dampers, the displacement response may increase the absolute acceleration response. In this study, semi-active control systems were investigated and the results of numerical simulation indicated that the systems could reduce not only the relative displacement between deck and pier, but can also reduce the absolute acceleration responses effectively. This study also shows that a semi-active system need lower power than an active system. From the performance tests of the MR damper it is found that a restoring force of $1600 \mathrm{~N}$ can be reached only with $4 \mathrm{~V}$ supplied to the damper. In the example of the isolated bridge this study has conducted only on numerical simulation and verification through experiment on the control efficiency will be needed in the future study.

\section{REFERENCES}

1. Dyke SJ, Spencer BF, Sain MK, Carlson JD. Modeling and control of magnetorheological dampers for seismic response reduction. Smart Materials and Structures 1996; 5:565-575.

2. Dyke SJ, Spencer BF, Sain MK, Carlson JD. Experimental verification of semi-active control strategies using acceleration feedback. Proceedings of 3rd International Conference on Motion and Vibration Control 1996; 3: 291-296.

3. Carlson JD, Spencer BF. Magnetorheological fluid dampers for semi-active control. Proceedings of the 3rd International Conference on Motion and Vibration Control 1996; 3:35-40.

4. Spencer BF, Dyke SJ, Sain MK, Carlson JD. Phenomenological model for magnetorheological dampers. ASCE Journal of Engineering Mechanics 1997; 123(3):230-238.

5. Lin PY, Chung LL, Loh CH, Cheng CP, Roschke PN, Chang CC. Experimental study of seismic protection for structures using MR dampers. Proceedings of 12 ECEE, London, September 2002, Paper 249.

6. Li WH, Yao GZ, Chen G, Yeo SH, Yap FF. Testing and state modeling of a MR damper under sinusoidal loading. Smart Materials and Structures 2000, 9:95-102. 
7. Sadek F, Mohtaz B. Semi-active control algorithms for structures with variable dampers. ASCE Journal of Engineering Mechanics 1998; 124(9):981-990.

8. Niwa N, Kobori T, Takahashi M, Midorikawa H, Kurata N, Mizuno T. Dynamic loading test and simulation analysis of full-scale semi-active hydraulic damper for structural control. Earthquake Engineering and Structural Dynamics 2000; 29:789-821.

9. Wongprasert N, Symans MD. Seismic response control of nonlinear base isolated structures using variable fluid dampers. Smart Structures and Materials 2001; 10:333-344.

10. Ruangrassamee A, Kawashima K. Semi-active control of bridges with use of magnetorheological dampers. Smart Structures and Materials 2001; 10:323-332.

11. Jansen LM, Dyke SJ. Semi-active control strategies for MR dampers: comparative study. ASCE Journal of Engineering Mechanics 2000; 126:795-803.

12. Chassiakos AG, Masri SF, Smyth AW, Caughey TK. On-line identification of hysteretic systems. Transaction of the ASME 1998; 65:194-203. 